\title{
PERSPEKTIF PENDIDIKAN KARAKTER AKHLAK MULIA PADA PERUBAHAN TINGKAH LAKU SISWA
}

\author{
Junil Adri', Ambiyar ${ }^{2}$, Refdinal $^{3}$, Muhammad Giatman ${ }^{4}$, \\ Azmil Azman ${ }^{5}$ \\ 1,2,3 Teknik Mesin Universitas Negeri Padang, Jalan Prof. Dr. Hamka Air Tawar, Padang \\ ${ }^{4}$ Teknik Sipil Universitas Negeri Padang, Jalan Prof. Dr. Hamka Air Tawar, Padang \\ ${ }^{5}$ Teknik Mesin Universitas Ekasakti, Jalan Veteran, Padang \\ 1e-mail: juniladri@ft.unp.ac.id
}

\begin{abstract}
Abstrak
Penelitian bertujuan untuk mendapatkan informasi penerapan pendidikan karakter akhlak mulia sebagai upaya pembentukan karakter siswa. Penelitian menggunakan metode deskriptif kualitatif. Subjek penelitian yaitu siswa jurusan Teknik Mesin SMK Negeri 1 Tanjung Raya Kabupaten Agam Provinsi Sumatera Barat. Pemilihan subjek penelitian didasari kolaborasi penerapan program penanaman nilai rohani yang dilakukan ketua jurusan. Teknik pengambilan data dilakukan dengan observasi dan wawancara. Teknik analisis data menggunakan analisis deskriptif. Hasil penelitian mengungkapkan bahwa program pelaksanaan salat Zuhur berjemaah disambut positif oleh siswa; siswa telah patuh terhadap peraturan yang ada di sekolah; siswa lebih mementingkan perintah orang tua walaupun sedang asyik bermain dengan temannya; siswa memiliki respek terhadap lingkungan masyarakat; dan siswa memiliki jiwa cinta alam dan berbudaya menjaga lingkungan.
\end{abstract}

Kata Kunci: pendidikan karakter, akhlak mulia, perubahan tingkah laku.

\begin{abstract}
The research aimed to obtain information on the application of moral character education as an effort to build student character. This research used a qualitative descriptive method. The research subjects were students majoring in Mechanical Engineering at SMK Negeri 1 Tanjung Raya Agam Regency, West Sumatra Province. The selection of research subjects was based on collaborative implementation of the spiritual value cultivation program carried out by the head of the department. The data collection technique was carried out by observation and interviews. The data analysis technique used descriptive analysis. The results of the research revealed that the Zuhur prayer program in congregation was positively welcomed by the students; students have obeyed the rules in school; students are more concerned with parental orders even though they are enjoying playing with their friends; students have respect for the community environment; and students have a spirit of love for nature and a culture of protecting the environment.
\end{abstract}

Keywords: character education, noble morals, change in behavior.

\section{PENDAHULUAN}

Memasuki zaman globalisasi, hal yang sangat penting dipersiapkan untuk menghadapinya adalah dengan membentuk sumber daya manusianya menjadi lebih baik (Johan, 2014). Namun tidak hanya baik dalam hal pengetahuan dan teknologi, tapi juga baik dalam hal sikap. Pembentukan karakter perlu dilakukan sejak usia dini. Pembentukan karakter akhlak mulia pada setiap anak adalah 
pondasi dasar untuk membangun suatu bangsa agar menjadi maju. Sebab kemajuan suatu bangsa hanya dapat dicapai dalam masyarakat yang pemimpinnya memiliki karakter kuat. Banyak pemimpin bangsa yang mempunyai intelektualitas yang tinggi, namun sedikit sekali memiliki karakter akhlak mulia (Ahmad, 2015). Hal lain juga terjadi pada kaum pelajar. Perilaku pelajar sudah sangat jauh dari nilai moral (Johan, 2014). Permasalahan free sex (seks bebas), tawuran antarpelajar, dan tindakan kriminal di kalangan pemuda semakin sering terjadi.

Berkurangnya kemampuan pengendalian diri di kalangan pemuda dan remaja membuktikan turunnya nilai keimanan dan ketakwaan (Zuchdi, dkk., 2010). Bangsa Indonesia yang didasari Pancasila sejatinya memiliki nilai etika dan karakter yang kuat. Kenyataan yang terjadi memperlihatkan bahwa nilai karakter yang dimiliki generasi muda Indonesia semakin menurun dengan banyaknya fenomena pelanggaran yang dilakukan. Pemerintah telah melakukan berbagai upaya untuk menanamkan nilai karakter pada generasi muda (Juwitaningrum, 2013). Untuk mewujudkan bangsa yang berkarakter tersebut, pemerintah merencanakan beberapa ruang lingkup sasaran pembangunan karakter bangsa salah satunya adalah lingkup satuan pendidikan. Undang-Undang Republik Indonesia Nomor 20 Tahun 2003 tentang Sistem Pendidikan Nasional menyatakan bahwa pendidikan nasional selain untuk mencerdaskan juga memiliki peranan menanamkan nilai karakter kepada generasi muda dalam upaya amenciptakan bangsa yang bermartabat.

Kepemilikan nilai karakter akan mencerminkan kemuliaan yang dimiliki. Nilai karakter akan menaikkan derajat dan martabat individu (Sumardjoko, 2010). Pentingnya ahklak mulia menjadikan individu respek terhadap lingkungan. Akhlak juga berkaiatan dengan nilai keimanan. Individu yang memiliki tingkat keimanan yang baik akan mampu memanajemen diri lebih baik dan menyelesaikan permasalahan secara tenang dan penuh pertimbangan (Zuchdi, dkk., 2010). Pembentukan karakter yang baik penting dimiliki oleh siswa agar bisa dihargai oleh siapapun, baik di lingkungan sekolah maupun lingkungan masyarakat. Guru berperan sebagai orang tua siswa di sekolah. Selain memberikan layanan akademis di bidang akademik, guru juga memiliki peranan 
yang besar dalam membentuk kepribadian siswanya (Osman, dkk., 2009). Peranan guru, perangkat sekolah, fasilitas, dan sumber belajar harus diselaraskan agar penanaman nilai karakter benar-benar mampu memenuhi tujuan pendidikan nasional.

Jurusan Teknik Mesin SMK Negeri 1 Tanjung Raya Kabupaten Agam Provinsi Sumatera Barat telah mengahasilkan banyak lulusan yang bekerja di industri dan dunia kerja. Kualitas kelulusan siswa tidak hanya ditentukan oleh tingginya intelektualitas pengetahuan maupun keterampilannya saja, akan tetapi juga membutuhkan sikap moral atau karakter yang baik, agar nantinya bisa diterima di mana saja, baik di lingkungan perguruan tinggi, lingkungan kerja, maupun lingkungan masyarakat. Observasi awal dilakukan dengan mewawancarai dua orang gur mata pelajaran produktif dan dua orang guru mata pelajaran umum.

Hasil observasi disimpulkan perspektif guru menilai $45 \%$ siswa yang mampu menerapkan ahklak mulia dalam keseharian di sekolah. Kebanyakan siswa lebih sering melanggar peraturan sekolah dan bersikap kurang baik dengan orang lain. Pelanggaran yang dilakukan yaitu sering datang terlambat ke sekolah dan kurang disiplin dalam mengerjakan tugas. Sikap yang ditunjukkan siswa dalam berinteraksi juga belum mencerminkan nilai kesopanan. Namun Tindakan yang dilakukan siswa tersebut telah mendapat tindakan tegas dari sekolah. Komisi penindakan kedisiplinan sekolah memberikan sangsi sosial bagi siswa yang terlambat masuk ke kelas. Walaupun sekolah sudah memberikan sanksi kepada siswa, namun belum memberikan efek jera terhadap siswa. Pelanggaran terlambat datang ke sekolah masih terjadi dan masih adanya siswa yang memakai sandal atau sepatu yang tidak berwarna hitam ke sekolah.

Temuan awal penelitian diperkuat dengan hasil wawancara dengan sepuluh orang siswa Jurusan Teknik Mesin SMK Negeri 1 Tanjung Raya. Hasilnya dapat disimpulkan bahwa kebanyakan dari siswa sudah mengetahui aturan yang ada di sekolah. Namun siswa belum sepenuhnya menjalankan apa yang tertulis dalam peraturan tersebut. Rata-rata siswa belum menjalankan aturan dengan baik, hal tersebut terlihat dari sikap acuh tak acuhnya dengan peraturan yang dibuat oleh sekolah. 
Salah satu penyebab dari timbulnya rasa acuh tak acuh terhadap peraturan tersebut adalah karena belum maksimalnya peranan guru dalam mengawasi perilaku siswa di sekolah. Dalam pelaksanaan proses pembelajaran, ketercapaian tujuan pembelajaran bidang kompetensi menjadi hal utama, guru fokus bagaimana siswa tersebut mengerti dengan materi pelajaran yang disampaikannya. Akibatnya sikap siswa menjadi belum terbentuk dengan baik. Diperlukan perhatian yang serius dalam menangani masalah tersebut oleh seluruh elemen sekolah. Pembentukan akhlak pada siswa sangat penting dilakukan (Darojah, 2016). Pembentukan akhlak dapat dilakukan dengan pemberian contoh perilaku terpuji kepada siswa. Setiap pembelajaran selalu diawali dengan siraman rohani yang berkaitan dengan materi pembelajaran (Darojah, 2016). Banyak cara memberntuk akhlak mulia pada siswa. Salah satunya adalah dengan kegiatan ekstrakulikuler di sekolah, diantaranya yaitu wirid rohaniah (Mualimin, 2010).

Karakter merupakan sifat pribadi yang ada dalam diri seseorang yang dibangun secara terus-menerus sehingga membentuk akhlak, budi pekerti, dan perilaku yang membedakan cara bersikap seseorang dengan orang lain. Setiap individu memiliki karakter yang berbeda-beda, meskipun individu tersebut berada dalam lingkungan yang sama atau bahkan kembar identik sekalipun (Suriansyah dan Aslamiah, 2015). Pendidikan karakter menjadi upaya yang dilakukan dalam membentuk perilaku peserta didik (Siregar, 2016). Penerapan pendidikan karakter yang sistematis menjadi kunci pembentukan akhlak. Akhlak yang dibentuk berhubungan dengan Tuhan, sesama manusia, dan lingkungan. Akhlak diimplementasikan dalam sikap, perasaan, dan tata kerama (Abdullah, 2014). Di Indonesia, pendidikan karakter telah diimplementasikan dalam pendidikan nasional. Tujuan pendidikan karakter untuk membentuk generasi muda yang memiliki akhlak. Pendidikan karakter juga mendukung proses dan hasil dari pelaksanaan pendidikan.

Kata akhlak dalam Kamus Bahasa Indonesia memiliki makna perangai, adat istiadat, tabiat atau sistem perilaku yang dibuat (Poerwadarminta, 2016). Berdasarkan istilah, kata akhlak berarti sikap individu yang diimplementasikan dalam perbuatan dan tingkah laku. Perbuatan baik yang dilakukan seseorang harus 
berdasarkan akal dan agama. Bila terdapat kesesuaian tingkah laku dengan akal dan agama, maka dapat disebut sebagai akhlakul karimah atau akhlak mulia (Khodijah, 2013).

Berdasarkan permasalahan yang telah diuraikan, maka penelitian bertujuan untuk mendapatkan informasi penerapan pendidikan karakter akhlak mulia sebagai upaya pembentukan karakter siswa jurusan Teknik Mesin SMK Negeri 1 Tanjung Raya Kabupaten Agam Provinsi Sumatera Barat.

\section{METODE}

Metode penelitian yaitu deskriptif kualitatif. Penerapan perlakuan penanaman nilai akhlak mulia pada siswa yang menjadi program ketua jurusan Teknik Mesin yang diintegrasikan dalam pembelajaran yang dilakukan oleh guru. Teknik sampling yang digunakan adalah total sampling. Subjek penelitian yaitu seluruh siswa kelas $\mathrm{X}$ jurusan Teknik Mesin di SMK Negeri 1 Tanjung Raya Kabupaten Agam Provinsi Sumatera Barat. Subjek penelitian berjumlah 37 orang. Pembatasan subjek penelitian pada siswa kelas $\mathrm{X}$ dikarenakan siswa kelas $\mathrm{X}$ masih dalam masa transisi dari sekolah tingkat pertama sehingga mudah dalam pembinaan.

Teknik pengumpulan data menggunakan observasi dan wawancara. Peneliti melakukan observasi selama 3 minggu dengan melakukan pengamatan tentang bagaimana perspektif pendidikan karakter akhlak mulia pada perubahan tingkah laku yang telah diterapkan pada subjek penelitian.

Tabel 1 Pedoman Observasi

\begin{tabular}{ll}
\hline \multicolumn{1}{c}{ Akhlak Mulia } & \multicolumn{1}{c}{ Indikator } \\
\hline Dzikrullah & $\begin{array}{l}\text { Salat Zuhur berjemaah di masjid. } \\
\text { Berani berkata benar } \\
\text { Berani mengemukakan pendapat dan menjawab } \\
\text { pertanyaan guru. } \\
\text { Tidak absen dan tidak terlambat masuk ke kelas. } \\
\text { Tolong-menolong }\end{array}$ \\
$\begin{array}{l}\text { Menjaga alam dan } \\
\text { lingkungan }\end{array}$ & Menjaga kebersihan kelas dan pekarangan sekolah. \\
\hline
\end{tabular}


Teknis pelaksanaan wawancara dilakukan setelah jam pelajaran usai. Kegiatan wawancara dilaksanakan secara bergantian, dalam satu hari kegiatan wawancara dilaksanakan kepada 5 siswa.

Tabel 2 Indikator Pedoman Wawancara

\begin{tabular}{lll}
\hline Akhlak Mulia & Pertanyaan & Kesimpulan \\
\hline Akhlak berhubungan dengan Tuhan & & \\
Akhlak terhadap diri sendiri & & \\
Akhlak terhadap keluarga & & \\
Akhlak terhadap masyarakat & \\
Akhlak terhadap alam & \\
\hline
\end{tabular}

Pedoman wawancara memiliki lima indikator. Pada indikator akhlak yang berhubungan dengan Tuhan memiliki sub indikator tauhid, berdoa, dzikrullah, dan tawakal. Untuk indikator akhlak terhadap diri sendiri memiliki sub indikator sabar, syukur, tawadhu', iffah, hilmun, jujur, dan berani berkata benar. Indikator akhlak terhadap keluarga memiliki sub indikator berbakti kepada orang tua, adil terhadap saudara, dan membina serta mendidik keluarga. Indikator akhlak terhadap masyarakat memiliki sub indikator ukhuwah atau persaudaraan, tolongmenolong, adil, pemurah, penyantun, pemaaf, menepati janji, musyawarah, dan wasiat dalam kebenaran. Indkator akhlak terhadap alam memiliki sub indikator memanfaatkan alam.

Teknik analisis data yang digunakan yaitu analisis deskriptif diawali dengan reduksi data. Data yang dikumpulkan ditabulasi untuk disimpulkan. Langkah selanjutnya adalah menyajikan data. Penyajian data akan memudahkan dalam memahami tanggapan dari subjek penelitian. Langkah ketiga adalah penarikan kesimpulan. Penyimpulan didasari pada hal-hal penting yang berkaitan dengan indikator penelitian.

\section{HASIL DAN PEMBAHASAN}

Jadwal aktivitas kegiatan yang dilakukan siswa setiap hari di sekolah terlihat di Tabel 3. 
Tabel 3 Jadwal Aktivitas Siswa

\begin{tabular}{|c|c|}
\hline Jadwal (WIB) & Kegiatan \\
\hline Pukul 07.30 & Bel masuk sekolah mulai dibunyikan. \\
\hline Pukul $07.30-08.15$ & $\begin{array}{l}\text { Setiap Senin siswa mengadakan upacara bendera selama } \\
\text { satu jam sebelum masuk kelas. }\end{array}$ \\
\hline Pukul $08.15-10.30$ & $\begin{array}{l}\text { Siswa mulai belajar seperti biasa. Guru memberikan } \\
\text { materi pelajaran. }\end{array}$ \\
\hline Pukul $10.30-10.45$ & Siswa mulai istirahat yang pertama. \\
\hline Pukul $10.45-12.15$ & Siswa kembali belajar sekitar dua jam pelajaran. \\
\hline Pukul 12.15 - 12.45 & Siswa mulai istirahat yang kedua. \\
\hline Pukul 12.45 - 15.45 & $\begin{array}{l}\text { Siswa mulai belajar lagi selama tiga jam pelajaran sampai } \\
\text { bel pulang sekolah berbunyi. }\end{array}$ \\
\hline Pukul 15.45 & $\begin{array}{l}\text { Bel pulang sekolah berbunyi. Kecuali pada hari Jumat } \\
\text { dan Sabtu siswa pulang sekolah lebih cepat yaitu pada } \\
\text { pukul } 14.15 \text { WIB }\end{array}$ \\
\hline
\end{tabular}

Program ketua jurusan Teknik Mesin SMK Negeri 1 Tanjung Raya menyelaraskan seluruh guru yang mengajar pada mata pelajaran produktif dan umum untuk menanamkan nilai karakter akhlak mulia kepada siswa dalam pembelajaran. Ketua jurusan melakukan penyamaan persepsi melalui rapat dewan guru di jurusan Teknik Mesin. Program penanaman karakter yang dilakukan adalah mengkoordinasikan siswa untuk melaksanakan salat Zuhur berjemaah, meningkatkan keberanian siswa untuk berkata benar dalam segala hal, iffah atau tidak melakukan kesalahan, tolong-menolong antar-sesama dalam hal kebaikan, serta menjaga alam dan lingkungan melalui cinta kebersihan. Pelaksaan program didukung oleh seluruh guru. Observasi terhadap tingkah laku siswa dilaksanakan selama 4 minggu. Observasi dilakukan sesuai dengan jadwal aktivitas siswa. Hasil observasi dapat dilihat pada Gambar 1.

Program ketua jurusan yang dilaksanakan setiap guru di jurusan Teknik Mesin menujukkan perubahan perilaku siswa. Perilaku dilihat dari aktivitas yang dilakukan siswa. Nilai karakter yang pertama diamati adalah akhlak yang berhubungan dengan Tuhan. Akhlak berkaitan dengan kewajiban manusia sebagai makhluk Tuhan. Upaya yang dilakukan adalah dengan program salat Zuhur berjemaah yang dikoordinir oleh guru sesuai dengan jadwal pelajaran yang 
bertepatan dengan waktu salat tersebut. Dari wawancara yang dilakukan, siswa menyampaikan bahwa siswa menyadari kewajiban melaksanakan salat.

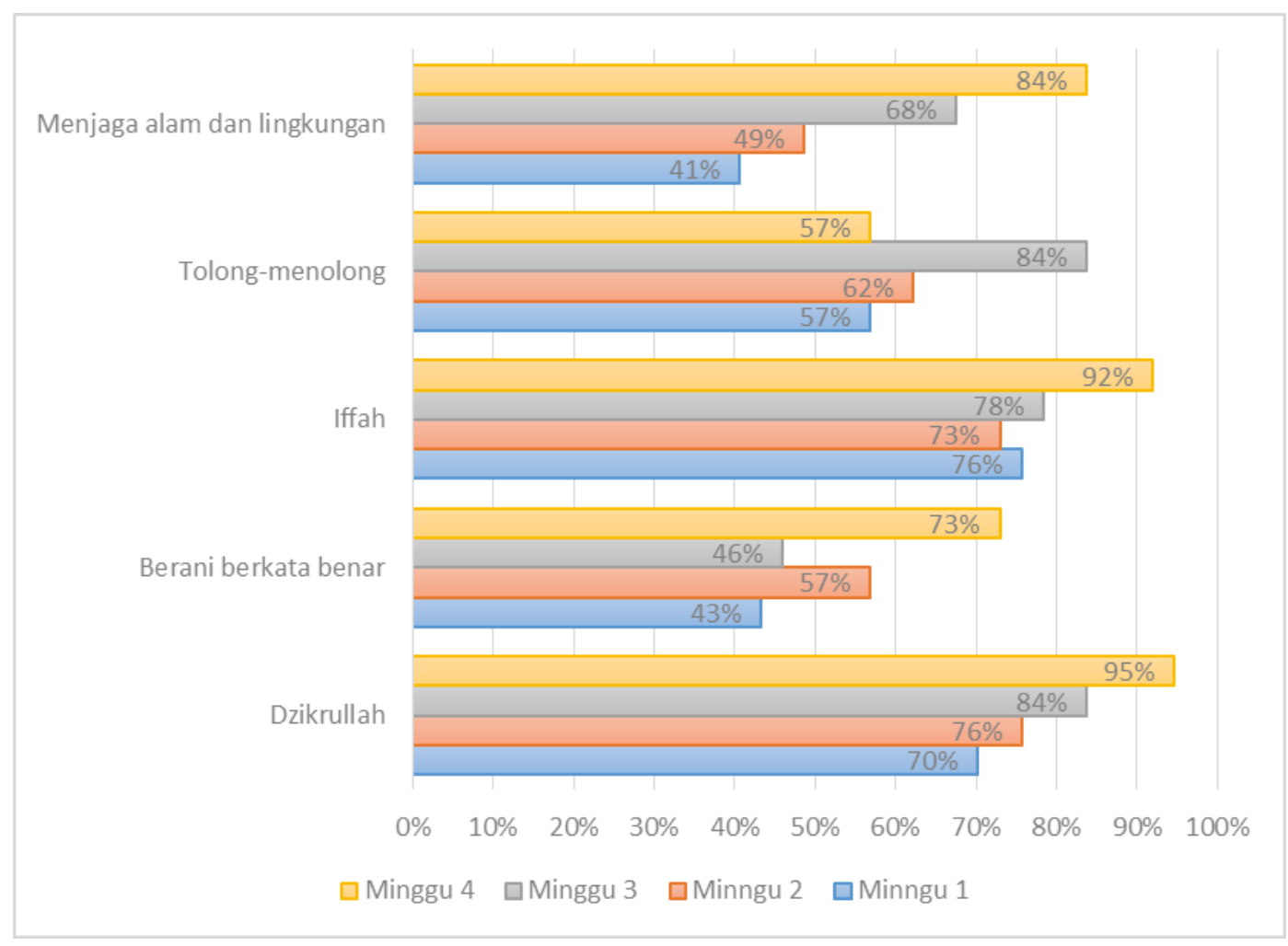

\section{Gambar 1 Hasil Observasi Tingkah Laku Siswa}

Program pelaksanaan salat Zuhur berjemaah disambut positif oleh siswa. Hasil observasi menunjukkan peningkatan jumlah siswa yang mengikuti salat berjemaah. Adapun pernyataan bagi siswa yang tidak mengikuti salat berjemaah mengatakan bahwa pelajaran praktikum pada jam pertama hingga jam ketujuh membuat pakaian kotor dan merasa tidak bersih untuk salat. Siswa memilih pulang ke tempat tinggalnya untuk mengganti baju dan melaksankan salat secara sendiri-sendiri. Manusia sebagai mahluk Allah memiliki kewajiban untuk menyembah kepada-Nya. Kesadaran diri untuk menyembah merupakan perwujudan rasa syukur. Kesadaran generasi muda untuk melaksanakan kewajiban cenderung rendah karena berbagai faktor, contohnya faktor lingkungan dan sosial (Syaepul, 2017).

Nilai karakter yang kedua adalah akhlak terhadap diri sendiri. Indiktor yang digunakan pada penilaian karakter yaitu sikap sabar, syukur, tawadhu' (rendah hati), iffah (tidak melakukan hal yang dilarang), hilmun (menahan amarah), jujur, 
dan berani berkata benar. Upaya yang dilakukan guru adalah dengan memberikan motivasi kepada siswa dalam setiap pembelajaran. Motivasi yang diberikan dengan memberikan contoh sikap teladan dalam kehidupan sehari-hari dan dikaitkan dengan materi yang diajarkan. Dari hasil observasi, rata-rata siswa sudah memiliki karakter akhlak terhadap diri sendiri. Dilihat dari capaian hasil observasi siswa telah patuh terhadap peraturan yang ada di sekolah dengan nilai persentase lebih dari 75\%. Pelanggaran yang masih sedikit terjadi adalah ketepatan waktu memasuki ruangan kelas saat pembelajaran dimulai.

Hasil penelitian untuk indikator berani berkata benar masih memiliki persentase cukup rendah dengan rerata 50\%. Hasil tersebut dijelaskan berdasarkan wawancara bahwa siswa masih malu untuk mengungkapkan apa yang dirasakan. Sikap percaya diri siswa masih rendah. Pemberian motivasi kepada siswa dapat memengaruhi ahklak siswa. Pemberian contoh motivasi yang mengkaitkan materi pembelajran dengan aplikatif sikap teladan dalam kehidupan sehari-hari lebih cepat dipahami siswa dan di terapkan dalam kesehariannya (Darojah, 2016). Sedangkan materi tentang pendidikan karakter membuat kesadaran diri sendiri semakin bertambah ke arah yang lebih baik (Lesmana, dkk., 2019; Yuliananingsih, 2015).

Nilai karakter yang ketiga yaitu akhlak terhadap keluarga. Nilai karakter tersebut dilihat dari sikap tolong-menolong siswa terhadap pekerjaan orang tua. Upaya yang dilakukan guru adalah dengan menjelaskan pentingnya orang tua, jasa orang tua, dan manfaat berbakti kepada orang tua. Hasil observasi menunjukkan bahwa siswa senantiasa membantu kegiatan orang tua di rumah. Persentase akhlak terhadap keluarga berada pada 68\%. Hasil tersebut diperjelas dengan hasil wawancara dengan siswa. Siswa menyampaikan keihklasan dalam membantu pekerjaan orang tua seperti membantu membersihkan rumah, menolong ayah ke sawah, dan membantu pekerjaan orang tua lainnya. Bahkan kebanyakan siswa lebih mementingkan perintah orang tua walaupun sedang asyik bermain dengan temannya. Sebagian siswa menyampaikan bahwa tidak dapat membantu orang tua karena tinggal di dekat sekolah yang jauh dari rumah. Namun demikian, saat siswa pulang kampung, siswa senantiasa membantu 
pekerjaan orang tua. Membantu orang tua menjadi rahmat untuk lancarnya jalan hidup dan $50 \%$ anak yang menghormati orang tuanya memiliki sikap tenang dalam pembelajaran (Suriansyah dan Aslamiah, 2015). Rida orang tua akan memudahkan setiap urusan bagi anak yang berbakti.

Nilai karakter yang keempat adalah akhlak terhadap masyarakat. Manusia sebagai mahluk sosial tentunya memerlukan interaksi dengan orang lain. Upaya yang dilakukan guru adalah dengan menjelaskan pentingnya menghormati dan menghargai orang lain. Dalam lembar observasi nilai karakter akhlak terhadap masyarakat tergolong pada sikap saling tolong-menolong dan perduli terhadap lingkungan. Dilihat dari hasil observasi capaian pada indikator tersebut berada pada rerata $65 \%$. Hasil penelitian memang belum maksimal. Hasil penelitian menjelaskan bahwa siswa memiliki respek terhadap lingkungan masyarakat. Hasil tersebut diperkuat dengan hasil wawancara bahwa siswa ikut serta pada kegiatan yang ada di masyarakat. Adapun kegiatan yang diikuti seperti kegiatan gotong royong, ikut menjadi pemuda masjid, dan menjadi relawan kegiatan sosial. Penerapan pendidikan berbasis karakter dipengaruhi oleh lingkungan masyarakat, orang tua, guru, serta teman sehingga siswa memiliki akhlak dan bersikap serta bertingkah laku sesuai dengan karakter yang sesuai dengan norma-norma yang berlaku (Mualimin, 2010; Rianto, 2015; Octavia dan Rube'i, 2017; Azkia dan Tamrin, 2018).

Nilai karakter kelima adalah akhlak terhadap alam. Akhlak terhadap alam merupakan akhlak bagaimana manusia mencintai alam dan menjaga kelestariannya. Upaya yang dilakukan guru adalah dengan memberikan pemahaman kepada siswa kenapa harus mencintai alam. Membudayakan kebersihan lingkungan. Dari hasil obeservasi terlihat bahwa 65\% siswa memiliki jiwa cinta alam dan berbudaya menjaga lingkungan. Hasil observasi diperkuat dengan hasil wawancara kepada siswa bahwa siswa menyukai lingkungan yang bersih. Siswa melaksanakan kegiatan piket yang telah disusun sesuai dengan jadwal. Intruksi untuk dekorasi ruangan kelas dengan tanaman juga dilaksanakan siswa dengan baik. Indikator lemah yang didapatkan dalam karakter akhlak 
terhadap alam adalah kekonsistenan siswa dalam membuang sampah. Siswa masih belum seutuhnya melaksanakan kegiatan buang sampah pada tempatnya.

\section{SIMPULAN}

Berdasarkan hasil penelitian, disimpulkan bahwa program pelaksanaan salat Zuhur berjemaah disambut positif oleh siswa; siswa telah patuh terhadap peraturan yang ada di sekolah; siswa lebih mementingkan perintah orang tua walaupun sedang asyik bermain dengan temannya; siswa memiliki respek terhadap lingkungan masyarakat; serta siswa memiliki jiwa cinta alam dan berbudaya menjaga lingkungan.

\section{DAFTAR PUSTAKA}

Abdullah, M. A. 2014. Religion, Science and Culture: An Integrated, Interconnected Paradigm of Science. Aljamia'ah Journal of Islamic Studies, 52(1): 175-203.

Ahmad, H. 2015. Leadership in TVET for the 21st Century: Challenges, Roles and Characteristics. Procedia - Social and Behavioral Sciences, 195(July): 1471-1476.

Azkia, H. \& Tamrin, M. 2018. Upaya Mengoptimalisasikan Pendidikan Berbasis Karakter Siswa TPQ/TQA Masjid Darul Mukhlisin Padang. Gervasi: Jurnal Pengabdian kepada Masyarakat, 2(1): 47-56.

Darojah, S. 2016. Metode Penanaman Akhlak dalam Pembentukan Perilaku Siswa MTs N Ngawen Gunungkidul. Jurnal Pendidikan Madrasah, 1(November): 233-244.

Johan, A. B. 2014. Peran Pendidikan Kejuruan dalam Menghadapi Masyarakat Ekonomi ASEAN (MEA). Jurnal Akademik Universitas Sarjanawiyata Tamansiswa (UST) Yogyakarta, 2015(November): 1-6.

Juwitaningrum, I. 2013. Program Bimbingan Karir untuk Meningkatkan Kematangan Karir Siswa SMK. PSIKOPEDAGOGIA Jurnal Bimbingan dan Konseling, 2(2), 132-147.

Lesmana, C., Arpan, M., Ambiyar, Wakhinuddin, \& Fatmawati, E. 2019. Respons Mahasiswa terhadap Pelaksanaan Program Matrikulasi. Edukasi: Jurnal Pendidikan, 17(2): 227-237.

Khodijah, N. 2013. Kinerja Guru Madrasah dan Guru Pendidikan Agama Islam Pasca Sertifikasi di Sumatera Selatan. Jurnal Cakrawala Pendidikan, 5(1): 91-102.

Mualimin. 2010. Pembinaan Pendidikan Karakter Akhlak Mulia melalui Ekstrakurikuler. Al-Hikmah Jurnal Agama dan Ilmu Pengetahuan, 12(1): 94-116.

Octavia, E. \& Rube'i, M. A. 2017. Penguatan Pendidikan Karakter Berbasis 
Pancasila untuk Membentuk Mahasiswa Prodi PPKn Menjadi Warga Negara yang Baik dan Cerdas. Sosial Horizon: Jurnal Pendidikan Sosial, 4(1): 111-124.

Osman, K., Hamid, S. H. A., \& Hassan, A. 2009. Standard Setting: Inserting Domain of the 21st Century Thinking Skills into the Existing Science Curriculum in Malaysia. Procedia - Social and Behavioral Sciences, 1(1): 2573-2577.

Undang-Undang Republik Indonesia Nomor 20 Tahun 2003 tentang Sistem Pendidikan Nasional dalam http://luk.staff.ugm.ac.id/atur/UU202003Sisdiknas.pdf. Diakses 9 Juli 2020.

Poerwadarminta, W. J. S. 2016. Kamus Besar Bahasa Indonesia Edisi Ketiga. Jakarta: Balai Pustaka.

Rianto, H. 2015. Peran Pendidikan Pancasila dan Kewarganegaraan Membangun Generasi Cerdas dan Berkarakter. Sosial Horizon: Jurnal Pendidikan Sosial,2(1): 14-21.

Siregar, A. J. 2016. Student Engagement dan Parent Involvement sebagai Prediktor Prestasi Belajar Matematika Siswa SMA Yogyakarta. Indigenous Jurnal Ilmiah Psikologi, 1(1): 61-73.

Sumardjoko, B. 2010. Faktor-Faktor Determinan Peran Dosen dalam Penjaminan Mutu Perguruan Tinggi. Jurnal Cakrawala Pendidikan, 3(3): 294-310.

Suriansyah, A. \& Aslamiah. 2015. Strategi Kepemimpinan Kepala Sekolah, Guru, Orang Tua, dan Masyarakat dalam Membentuk Karakter Siswa. Jurnal Cakrawala Pendidikan, 2(2): 234-247.

Syaepul, M. 2017. Pembinaan Akhlak Mulia melalui Keteladanan dan Pembiasaan. Jurnal Pendidikan Agama Islam-Ta'lim, 1(2): 49-65.

Yuliananingsih. 2015. Pelaksanaan Pendidikan Karakter di Program Studi Pendidikan Pancasila dan Kewarganegaraan IKIP PGRI Pontianak. Edukasi: Jurnal Pendidikan, 13(2): 239-248.

Zuchdi, D., Prasetya, Z. K., \& Masruri, M. S. 2010. Pengembangan Model Pendidikan Karakter Terintegrasi dalam Pembelajaran Bidang Studi di Sekolah Dasar. Cakrawala Pendidikan Jurlan Ilmiah Pendidikan, XXIX(3): $1-12$. 